\title{
Neuropsychological findings in personality disorders: A.R. Luria's approach
}

\author{
Ilia V. Pluzhnikov ${ }^{\mathrm{a}^{*}}$, Vasily G. Kaleda ${ }^{\mathrm{b}}$ \\ ${ }^{a}$ Lomonosov Moscow State University, Moscow, Russia \\ ${ }^{\mathrm{b}}$ State Scientific Institution The Mental Health Research Center, Moscow, Russia \\ *Corresponding author. E-mail: pluzhnikov.iv@gmail.com
}

There is a lack of information concerning the features of cognitive processes in personality disorders, as well as the brain mechanisms of the pathogenesis of these diseases. Luria's neuropsychological approach demonstrated its heuristicity in estimating the cognitive status of patients with mental disorders and can be employed to identify the brain bases of non-psychotic mental disorders (including personality disorders).

The objective of this research is to study the features of neurocognitive functioning in patients with schizoid personality disorder and schizotypal personality disorder (against the norm), employing Luria's neuropsychological methodology. Hypotheses: 1) While both types of personality disorders are related to schizophrenia spectrum disorders, the specificity of the neurocognitive functioning of each personality disorder will be observed in addition to general neuropsychological signs. Specific neuropsychological symptoms point to different brain deficits, which allows conclusion to be drawn regarding differences in the pathogenesis of each personality disorder; and 2) Luria's methodology neuropsychology is adequate for the study of neurocognitive functioning in personality disorders.

The study was conducted using qualitative and quantitative analyses (according to Luria) of neuropsychological testing data in a group of fifty male patients aged 19,2 $\pm 3,7$ years with pathocharacteristic domain disorders. The group consisted of 30 schizoid personality disorder patients and 20 schizotypal personality disorder patients.

Statistically significant differences $(p<0,005)$ in neurocognitive function (regulatory processes, memory, spatial function) between the healthy controls and patients with personality disorders were observed.

Specific cognitive disorders pointing to the dysfunction of front-thalamoparietal connections were characteristic of both groups. Lateral differences were discovered for both patient groups. The neuropsychological symptoms related to left hemisphere dysfunction were characteristic of the patients with schizotypal personality disorder. Neurocognitive deficits related to right hemisphere deficiency characterized the patients with schizoid personality disorder.

Keywords: neuropsychology, cognitive functions, personality disorders, cerebral mechanisms, pathogenesis 


\section{Introduction}

The study of pathogenetic mechanisms of nonpsychotic adolescent age mental disorders is due to their high frequency, the considerable socio-economic burden placed on affective and neurotic states, drug addiction, behavior disorders, and suicide. Researchers pay special attention to the psychopathological, etiological, pathogenetic and therapeutic aspects of depressive states discovered at late adolescent and early mature ages (Kopeiko \& Oleichik, 2007; Oleichik, 2011). The diffusion of affective pathology during adolescences varies from 13 to 40 percent according to various sources (Marceli, 1998; Kopeiko \& Oleichik, 2007). Adolescent depression cases differ significantly from mood disorders, arising in a later age and exhibiting different clinical characteristics (Brodaty et al., 2005; Oleichik, 2011). These cases are specified by different psychosocial scars (Rohde, Lewinsohn, Seeley, 1994) associated with a greater number of comorbid mental disorders (Rohde, Lewinsohn \& Seeley, 1991), and double the risk of emergence of addictive behaviors (Chilcoat \& Breslau, 1998; Christie et al., 1988) and suicide (Balázs et al., 2013). However, only a third of patients seek help (Aalto-Setälä et al., 2002).

Cognitive disorders of one type or another attend almost all forms of mental pathology. Non-psychotic mental disorders (affective, neurotic and personality disorders) at an adolescent age substantially determine a patient's clinical picture in terms of higher educational and work load at this specific age (Kopeiko \& Oleichik, 2007; Oleichik, 2011). The latest research shows that the cognitive component of depression influences the quality of social (educational, occupational) adaption and everyday functioning (Evans et al., 2013). Considerable research is dedicated to studying cognitive disorders that accompany depressive and phobic anxiety disorders during adolescence. However, several authors find most of the questions (especially on the pathogenetic role of the mentioned group of symptoms) to be open because of the methodological dissociation of present-day approaches in studying cognition in psychiatry and clinical psychology.

Non-psychotic affective disorders during adolescence are represented by three large units (excluding organic depressions and drug-induced depressions): affective illnesses (bipolar disorder spectrum), personality disorders, and schizophrenia. Contemporary studies on neurocognitive functioning at these nosologies display three aspects. First, different authors apply diverse assessment complexes which do not stand on a single theoretical basis. This difference in approach leads to content inter-comparison conflicts and causes considerable difficulties for data analysis. Second, the majority of studies analyze the nosotypical "cognitive profile" and its connection to different clinical characteristics (e.g., psychopathological symptoms severity on scales, duration of disease, and therapy) and genetic polymorphisms (endophenotypic approach). Possible cerebric mechanisms of cognitive deficit sometimes are not considered, or the neuropsychological facts conflict with neurovisualization data. Third, most researchers study only a minor quantity of clinical variants in the nosologies concerned. Therefore, considering the sufficient understanding of bipolar affective disorder with moderate and 
hard severity phases, no neuropsychological studies on cyclothymia (soft bipolar disorder) exist. The neurocognitive profile of antisocial, borderline and schizotypal personality disorders has been well-studied. However, neuropsychological studies on other personality disorders (according to the international classifications standard) are either lacking or insufficient. Finally, only a small group of studies is dedicated to the neuropsychological analysis of adolescent pathology. The pathoplastic role of a pubertal factor is almost never considered. Most of the described drawbacks and restrictions in foreign neuropsychological research on non-organic mental disorders are noted by the authors themselves as well as by the authors conducting meta-analyses and reviews (Quraishi \& Frangou, 2002; Ruocco, 2005; Lenzenweger, 2010).

Thus, the problem with the investigation of pathogenetic mechanisms (including cerebric ones) in adolescent depression within different nosologies is still of high importance. It is thought that the usage of Luria's neuropsychological method of syndrome analysis is expedient in accomplishing the system description of cognitive disorders and discovering cerebral dysfunction in patients with personality disorders during adolescence. This method has demonstrated its adequacy and heuristic superiority for studying cognitive process dysfunction in the clinical picture of mental disorders of non-organic genesis (Sidorova, Kaleda \& Barkhatova, 2004; Ivanov \& Neznanov, 2008; Gurovich \& Shmukler, 2010).

The objective of this research is to study the features of neurocognitive functioning in patients with schizoid personality disorder and schizotypal personality disorder (against the norm), employing Luria's neuropsychological methodology. Hypotheses: 1) While both types of personality disorders are related to schizophrenia spectrum disorders besides general neuropsychological signs, specificity of neurocognitive functioning at each personality disorder will be observed. Specific neuropsychological symptoms will point to different brain deficits, which enables conclusions to be drawn concerning differences in the pathogenesis of each personality disorder; and 2) Lurias methodology neuropsychology is adequate for the study of neurocognitive functioning in personality disorders.

\section{Method}

Fifty adolescent male patients (16-25 years old) with non-psychotic mental disorders participated between 2010 and 2013 and were kept under in-patient treatment (chief, M.D. V.G. Kaleda) in the department for studying endogenous mental disorders and affective states at the Mental Health Research Center of Russian Academy of Medical Sciences (Director, Member of the Academy A.S. Tiganov). The patients were divided into two groups according to their nosological diagnoses: schizoid personality disorder (30 patients) and schizotypal personality disorder (20 patients). The control group consisted of 30 conventionally healthy men. The average age of the examined persons was $19.2 \pm 3.7$ years old, and the participants were consistent according to their social-demographic characteristics.

The diagnoses were conducted using a clinical-psychopathological method and on the basis of ICD-10 research criteria. The ground psychopathological syndrome 


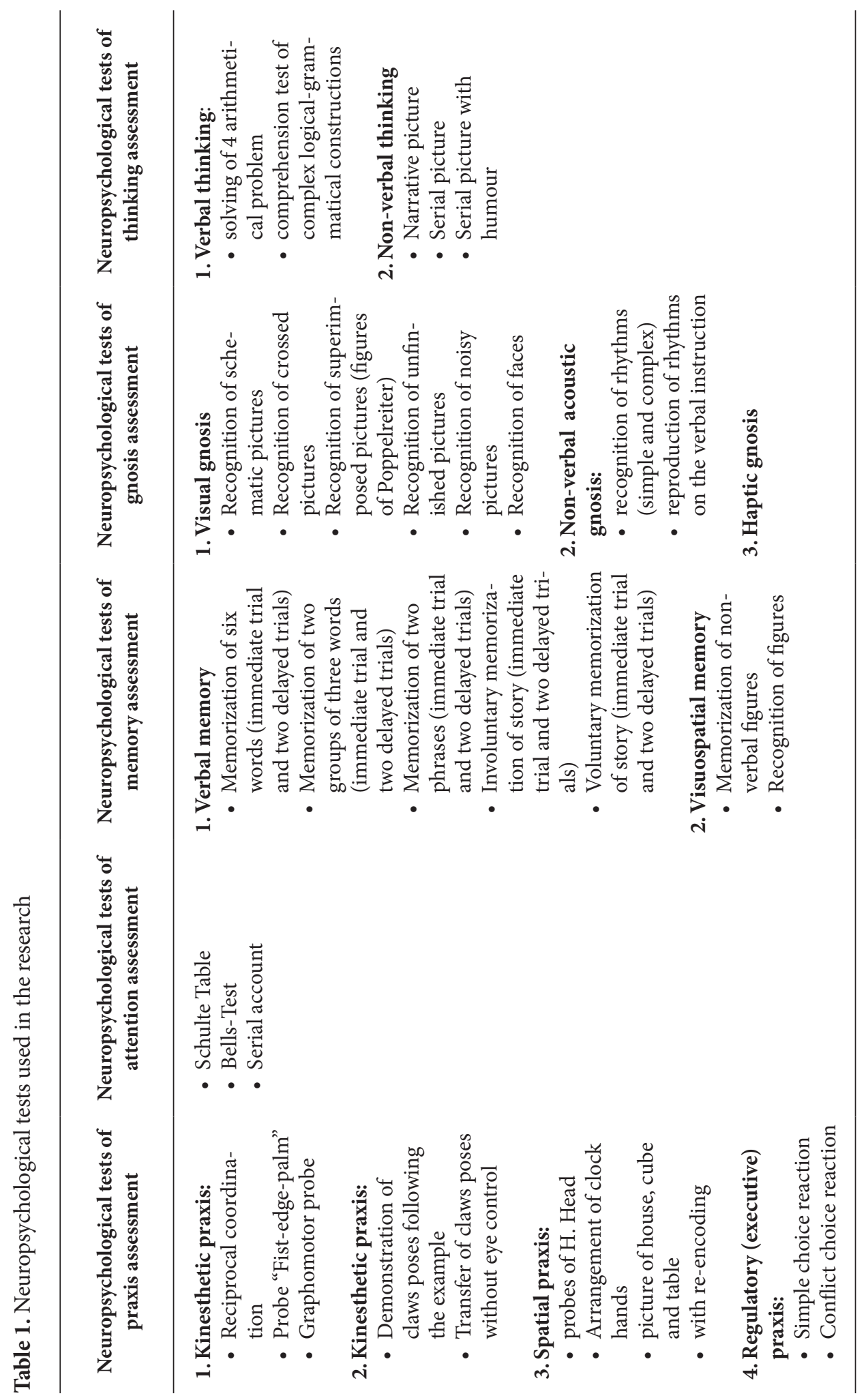


of all patients was a depressive state of a moderate severity with distinctive features and occurring during adolescence (Vladimirova, 1987; Oleichik, 2011).

The exclusion criteria were the following: age less than 16 or over 25 years, the occurrence of a psychotic state at present or in the past; organic pathology of CNS, defining the clinical picture of heavy chronic somatic diseases, drug addiction or mental retardation. All participants were dextral.

The neuropsychological assessment of the patients was conducted during the first week of treatment according to Luria's (1973b) scheme using a specially designed qualitative-quantitative scale. The used neuropsychological tests are presented in Table 1 . The results of each test were rated quantitatively according to a number of special qualitative subscales that related typical mistakes to a disorder of a specific neuropsychological factor. For example, when fulfilling the "Schematic sketch identification" there was an evaluation of not only visual paragnosia (disorder of the neuropsychological factor of visual analysis and synthesis) but also of fragmentary mistakes, chaotic character of structuring visual field, and visual perseverations (disorder of the neuropsychological factor of voluntary actions regulation - the neuropsychological executive factor). Points from each of the subscales (in all 438 points of rating) were summed and translated into T-points ( 0 through 3, where 0 is no disorder, 3 is a maximum degree of severity). Additionally, the following indices were created on basic neuropsychological factor functioning: executive control, kinetic, kineasthetic, tactile, auditory (verbal and non-verbal), spatial, visual, modally non-specific, energetic, and interhemispheric interaction. There were three macro-indices singled out according to Luria's conception on three structural functional blocks of the brain (Luria, 1973a). The participant groups were compared according to these indices using Mann-Whitney U-test criterion. Statistical analysis was performed using STATISTICA 9.0.

\section{Results}

The comparison of the data received after the neuropsychological examination indicated that the clinical group differed from the control group participants according to a number of parameters (indices) with different severities. The descriptive statistics are presented in Table 2.

The patients with schizoid personality disorder differed considerably from the healthy participants according to most of the indices (Fig. 1). There was an increase in the left hemisphere indices (Fig. 1) of "Executive function" ( $U=37.50, p=0.000)$ and "Kinetic action arrangement" $(\mathrm{U}=162.00, \mathrm{p}=0.020)$. Qualitative analysis revealed that the increase in these indices was associated with mistakes on the type of rigidity, programming and control (executive functions) in the arithmetic operation tasks and motor reaction choice. Operational kinetic mistakes in the form of movement automation glitches, bugs, tendencies toward rigid enhancement or program simplification occurred in the trials on serial action arrangement (mostly by the right hand) and intellectual operations. 
Table 2. Descriptive Statistics

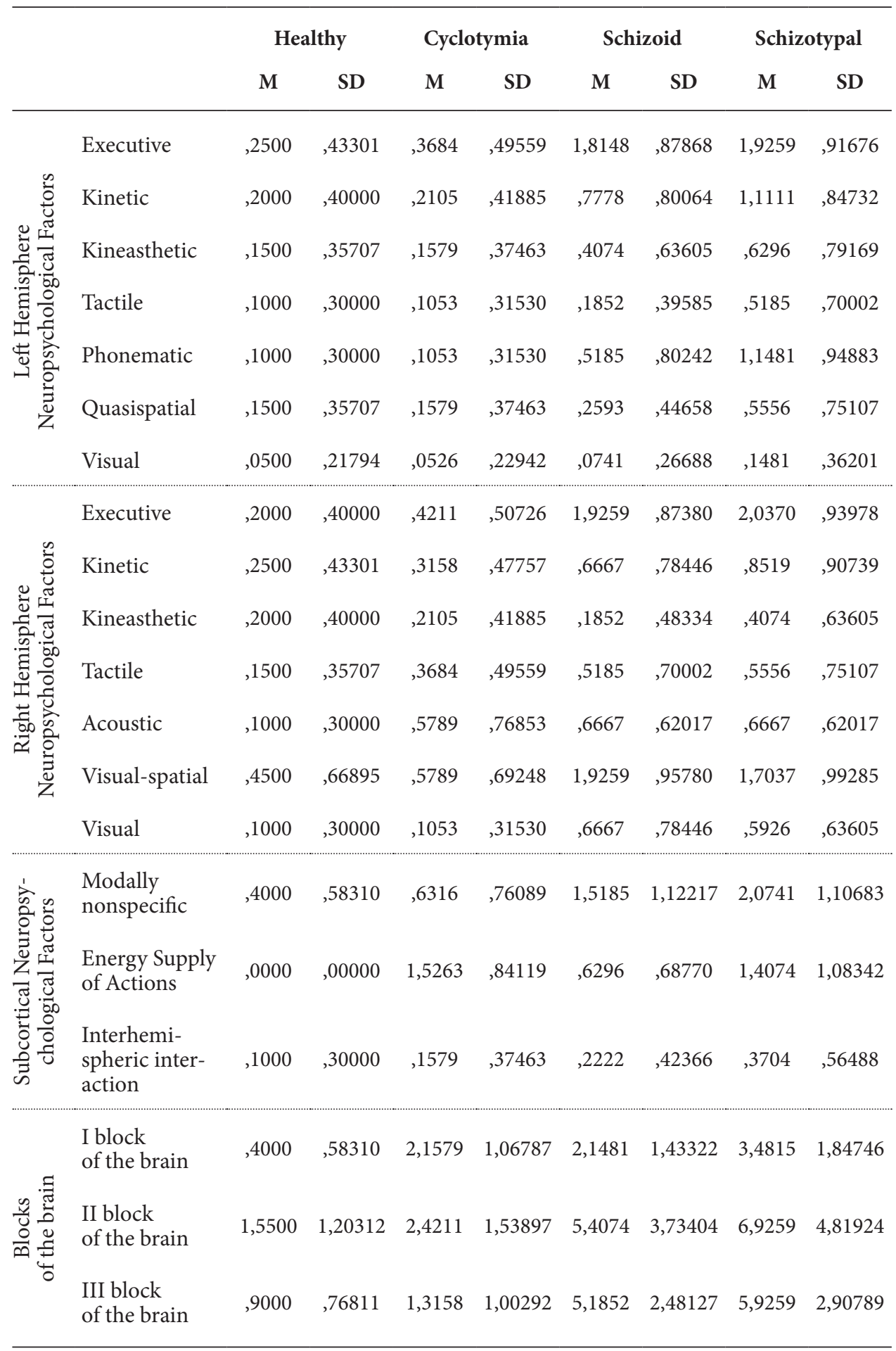




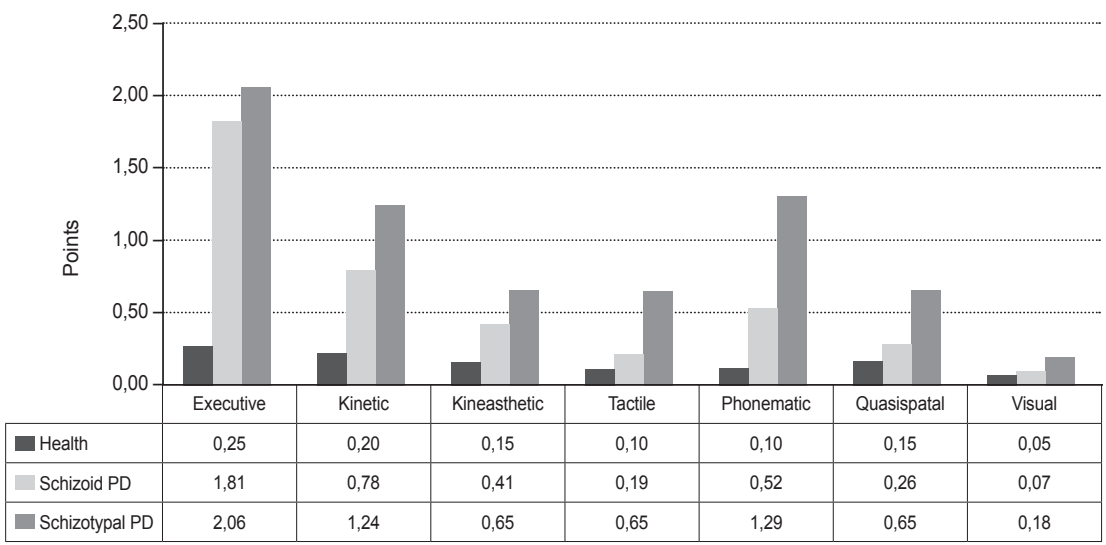

Figure 1. Indices of left hemispheric neuropsychological function factors, including mean values for the participant groups.

There were many more "right-hemispheric" indices compared to the norm (Fig. 2); these were the indices of "Executive function" ( $U=28.00, p=0.000)$ and "Visual-spatial analysis and synthesis" $(U=64.50, \mathrm{p}=0.000)$. The former had a high average that was determined by mistakes in the type of impulsion when accomplishing visual-figurative tasks by fragmentary perception and chaotic strategy of visual field structuring. The latter had non-gross mirror-like and metric mistakes. The increase of the "Modally non-specific factor" index $(U=119.00, p=0.001)$ was caused by the increased trace memory inhibition as a result of interference (independent upon memorized material modality). Furthermore, there were high average marks (Fig. 2 and 3) in the "Non-verbal acoustic analysis and synthesis" ( $U=135.00$, $\mathrm{p}=0.004)$ and "Energy Supply of actions" indices $(U=130.00, p=0.003)$. There was also an increase (Fig. 2) in the "Visual analysis and synthesis" index ( $U=162.00$, $\mathrm{p}=0.020$ ) that was determined by the presence of standard and a small number of non-standard paragnosia in the trials for identification of schematic, noisy and unfinished images.

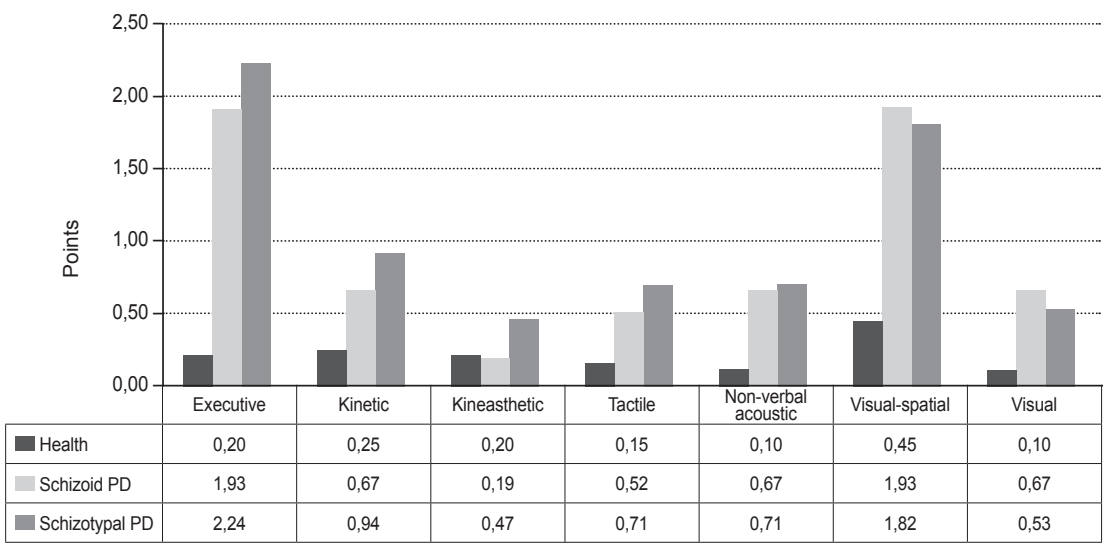

Figure 2. Indices of right hemispheric neuropsychological function factors. 


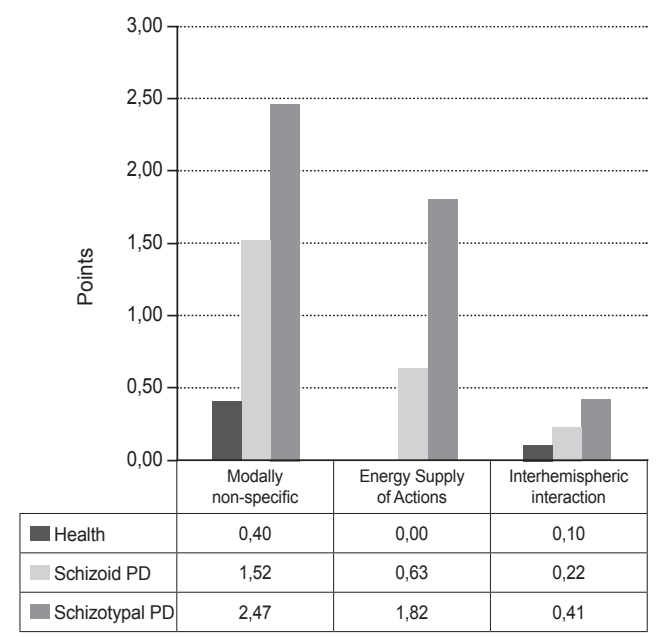

Figure 3. Indices of the neuropsychological factor function of subcortical structures of the brain.

The patients with schizotypal personality disorder were characterized by massive neuropsychological symptoms and differed significantly from the normal group. Compared to the healthy participants, there were no distinctions in the "left-hemispheric" indices, such as visual analysis and synthesis $(U=148.50$, $\mathrm{p}=0.512)$, kineasthetic factor $(\mathrm{U}=111.00, \mathrm{p}=0.072$, statistical trend-level $)$, quasispatial analysis and synthesis $(\mathrm{U}=112.50, \mathrm{p}=0.079$, statistical trend-level), in addition to the "right-hemispheric" index - kineasthetic factor $(\mathrm{U}=132.00$, $\mathrm{p}=0.246)$ and the "Interhemispheric interaction" index $(\mathrm{U}=110.00, \mathrm{p}=0.067$, statistical trend-level). In this regard, it appears to be expedient to compare the patients with a schizotypal personality disorder with the patients with a schizoid personality disorder. In comparison with the patient group with a schizoid personality disorder, the patients with a schizotypal disorder were characterized by a statistically significant increase in "left-hemispheric" indices (Fig. 1), including phonemic analysis and synthesis $(\mathrm{U}=124.50, \mathrm{p}=0.011)$, tactile analysis and synthesis $(\mathrm{U}=156.50, \mathrm{p}=0.078$, statistical trend-level $)$, quasispatial analysis and synthesis $(U=112.50, p=0.067$, and statistical trend-level). They also experienced a significant increase in two "subcortical" indices (Fig. 3), including energy supply of actions $(\mathrm{U}=89.50, \mathrm{p}=0.001)$ and modal-nonspecific factor $(\mathrm{U}=116.00$, $\mathrm{p}=0.006$ ). The latter caused an increase in the macroindex (Fig. 4) "I block of the brain" $(\mathrm{U}=74.50, \mathrm{p}=0.000)$. A high rate of the "Phonemic analysis and synthesis" index consisted of a great number of verbal and literal paraphasia, agrammatisms, and the problem of nomination in verbal and non-verbal trials in the patients of the given group. Some increase in the "Tactile analysis and synthesis" index was determined by accumulation of operational steregnostic mistakes (mostly righthanded) in the trial on object identification by means of touch feeling; and the increase in the "Quasispatial analysis and synthesis" index was determined by mistakes in understanding complex logic-grammatical constructions. A high rate of 
the macroindex "I block of the brain" (Fig. 4) in the given cohort (in comparison with the other two groups) was connected with trace memory inhibition under the influence of interference and the gross energy disorders of the type of quick exhaustion the patients experienced over the course of examination with an insufficient level of motivational regulation of mental tonus and decreased efficiency of cognitive processes.

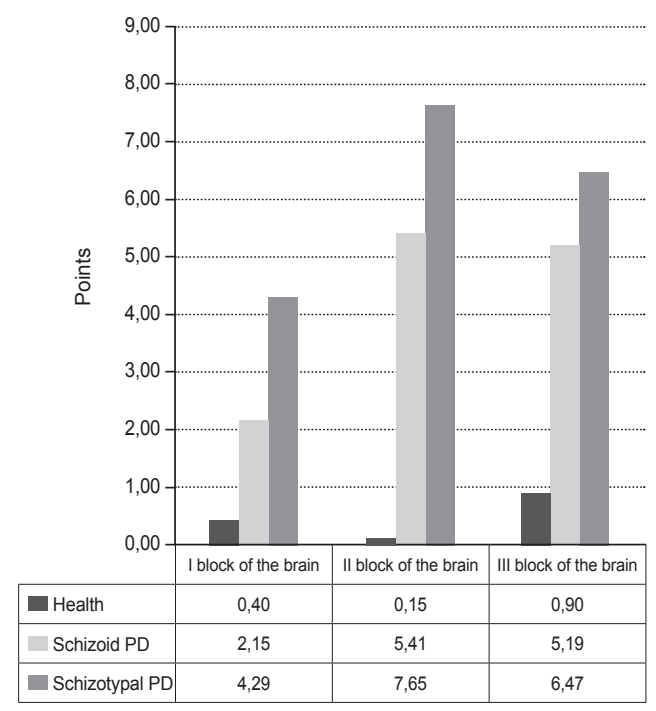

Figure 4. Indices of neuropsychological factor function within Luria's concept on three structural functional blocks of the brain.

\section{Discussion}

The conducted study demonstrated cognitive disorders as an integral part of the psychopathological structure on mental disorders in the field overlapping affective, pathocharacteristic and schizophrenic levels during adolescence. The neuropsychological approach demonstrated its adequacy in the arrangement of hypotheses on the pathogenetic links of the considered states.

In contrast to previous neuropsychological research on borderline (marginal) mental disorders during adolescence, there was an integrated methodology of Luria's neuropsychological syndrome analysis (1973a) used for the first time in this work. There was an analysis not only of separate mental processes but also the "functional organs" (intersecting links of mental functions, neuropsychological factors) of mental activity, as their state points to the degree of the function of certain cerebral mechanisms. Qualitative analysis of cognitive action disorders in neuropsychological situations enabled us to mark out nosotypical neuropsychological syndromes (metasyndromes) of the considered states.

The neuropsychological characteristics of schizoid personality disorder and schizotypal personality disorder differs by two features. The first is the presence of a particular, relatively non-specific neuropsychological symptom complex. This 
concerns the regular combination of executive dysregulation, memory reduction and spatial disorders discovered in both groups of patients. This symptom complex was described earlier (Korsakova \& Pluzhnikov, 2012) as "neuropsychological syndrome of adaption/dysadaptation" and connected with the dysfunction of the "constitutionally vulnerable axis" (front-thalamoparietal connections). It is considered as a task of neuropsychological conceptualization of compensation/decompensation syndrome (O.V. Kerbikov, N.I. Felinskaya, V.A. Guryeva, B.V. Shostakovich) in patients with psychopathic and psychopathic-like disorders within the "adaptation/dysadaptation" paradigm.

The second feature of the neuropsychological syndromology of the examined mental disorders showed neurocognitive disorders relatively typical of each of these groups. Except for the dysfunctions connected with the constitutionally vulnerable axis disturbance, the patients with schizoid personality disorder were characterized by the accumulation of neuropsychological symptoms caused by "weakness" of the temporal-parietal-occipital domain (secondary and tertiary, "associative" areas) of the right hemisphere of the brain, and disorders in the field of nonverbal auditory gnosis, visual-spatial and visual object perception. Patients with schizotypal personality disorders were characterized by a substantial severity and depth of neurocognitive disorders in comparison with the healthy participants and the patients in the two clinical groups. Additionally, an inverse neuropsychological picture was particular to the given patient group (distinguishing them from the patients with schizoid personality disorder) such that cognitive symptoms were connected with function deficiency in the rear departments of the left hemisphere of the brain, including paraphasia, agrammatisms, nomination mistakes, problems in understanding complex logical-grammatical constructions, and phenomena close to tactile agnosia (mostly by the right hand). These facts were in full conformity with the findings of foreign researchers (Raine, Lencz \& Mednik, 1995; Lenzenweger, 2010), whose works affirmed that deficiency in left-hemispheric (mostly verbal) function could be regarded as one of the central neurocognitive endophenotypes of schizotypy as a personality trait and schizotypal personality disorder as a nosological unit. It was also reported that this endophenotype was an important high-probability predictor of psychosis occurrence (Ritsner, 2011). The tactile sphere was also compromised early in the schizophrenic disorders spectrum (Zvereva, 1998).

\section{Conclusion}

In the course of this study, it was ascertained that there was an increase in the severity and depth of cognitive disorders with changes in their qualitative structure in the continuum from schizoidia (personality level) to mild endogenousprocess schizotypy. This increase should be considered when diagnosing and choosing a therapeutic strategy. The commonality of neuropsychological syndromology structure considering schizoid and schizotypal personality disorders could account for etiopathogenetic unity. However, lateral differences in the neuropsychological picture of each of the concerned anomalies proved a relative independence of schizoid status and schizotypy. The drawback of this 
study is that all of the patients were examined in a current depressive state that could have influenced the findings. The perspective of further studies is to study the neuropsychological syndromology of non-psychotic mental disorders during adolescence in patients with no positive symptoms (in a state of euthymia, compensation, and out of exacerbation) in connection with their social adaption and quality of life.

\section{References}

Aalto-Setälä, T., Marttunen, M., Tuulio-Henriksson, A., Poikolainen, K., \& Lönnqvist, J. (2002). Psychiatric treatment seeking and psychosocial impairment among young adults with depression. Journal of Affective Disorders, 70(1); 35-47. doi: 10.1016/S0165-0327(01)00316-0

Balázs, J., Miklósi, M., Keresztény, A., Hoven, C.W., Carli, V., Wasserman, C., Apter, A., Bobes, J., Brunner, R., Cosman, D., Cotter, P., Haring, C., Iosue, M., Kaess, M., Kahn, J.P., Keeley, H., Marusic, D., Postuvan, V., Resch, F., Saiz, P.A., Sisask, M., Snir, A., Tubiana, A., Varnik, A., Sarchiapone, M., \& Wasserman, D. (2013). Adolescent subthreshold-depression and anxiety: psychopathology, functional impairment and increased suicide risk. Journal of Child Psychology and Psychiatry, 54(6), 670-677. doi: 10.1111/jcpp.12016

Brodaty, H., Cullen, B., Thompson, C., Mitchell, P., Parker, G., Wilhelm, K., Austin, M.-P., \& Malhi, G. (2005). Age and gender in the phenomenology of depression. American Journal of Geriatric Psychiatry, 13(7), 589-596. doi: 10.1097/00019442-200507000-00007

Cerullo, M.A., Fleck, D.E., Eliassen, J.C., Smith, M.S., DelBello, M.P., Adler, C.M., \& Strakowski, S.M. (2012). A longitudinal functional connectivity analysis of the amygdala in bipolar I disorder across mood states. Bipolar Disorders, 14(2), 175-184.

Chilcoat, H. D., \& Breslau, N. (1998). Posttraumatic stress disorder and drug disorders. Testing causal pathways. Archives of General Psychiatry, 55(10), 913-917. doi:10.1001/ archpsyc.55.10.913

Christie, K. A., Burke J. D. Jr., Regier, D. A., Rae, D. S., Boyd, J. H., \& Locke, B. Z. (1988). Epidemiologic evidence for early onset of mental disorders and higher risk of drug abuse in young adults. American Journal of Psychiatry, 145(8), 971-975. http://dx.doi.org/10.1176/ ajp.145.8.971

Evans, V. C., Chan, S., Iverson, G. L., Bond, D. J., Yatham, L. N., \& Lam, R. W. (2013). Systematic review of neurocognition and occupational functioning in major depressive disorder. $\mathrm{Neu}$ ropsychiatry, 3(1), 97-105. doi: 10.2217/npy.13.3

Filatova T. V. (2000). Osobennosti poznavatelnoy deyatelnosti pri endogennykh depressiyakh s "yuvenilnoy astenicheskoy nesostoyatelnostyu" (neiropsikhologicheskoe issledovanie) [Cognitve actions characteristics of endogenous depressions with «juvenile asthenic disability» (neuropsychological research)]. (Unpublished doctoral thesis). Moscow.

Garrett, A., \& Chang, K. (2008). The role of the amygdala in bipolar disorder development. Development and Psychopathology, 20(4), 1285-1296. doi: 10.1017/S0954579408000618

Gurovich, I. Ya., \& Shmukler, A. B. (2010). Pervyipsikhoticheskiyepisod (problem ipsikhiatricheskayapomosh [The first psychotic episode (problems and psychiatric aid)]. Moscow: Medpraktika-M.

Quraishi, S., \& Frangou, S. (2002). Neuropsychology of bipolar disorder: a review. Journal of Affective Disorders, 72(3), 209-226. doi: 10.1016/S0165-0327(02)00091-5

Ivanov, M. V., \& Neznanov, N. G. (2008). Negativnye I kognitivnye rasstroystva pri endogennykh psikhozakh: Diagnostika, klinika, terapia [Negative and cognitive disorders in endogenous 
psychoses: Diagnostics, clinical picture and therapy]. Saint Petersburg: NIPNI in the name of V.M. Bekhterev.

Kaleda, V. G., Mezentseva, O. E., Krylova, E. S., \& Barkhatova, A. N. (2012). Osobennosti domanifestnogo etapa endogennogo psikhoza s pervym pristupom $\mathrm{v}$ yunosheskom vozraste [Pre-manifest phase characteristics of endogenous psychosis with the first episode during adolescence]. Zhurnal nevrologii i psikhiatrii imeni S.S. Korsakova [S.S. Korsakov Journal of Neurology and Psychiatry], 5, 22-28.

Kopeiko, G. I., \& Oleichik, I. V. (2007). Vklad pubertatnykh psikhobiologicheskikh protsessov $\mathrm{v}$ formirovanie i klinicheskie proiavlenia yunosheskikh depressiy [Contribution of pubertal psychobiological processes to the formation and clinical displays of adolescent depressions]. Zhurnal nevrologii i psikhiatrii imeni S.S. Korsakova [S.S. Korsakov Journal of Neurology and Psychiatry], 3, 4-17.

Korsakova, N. K., \& Pluzhnikov, I. V. (2012). Neiropsikhologicheskiypodkhod k Izucheniyuprotsessovadaptatsii [Neuropsychological approach to adaptive process]. In T.V. Akhutina \& Zh.M. Glozman (Eds.), Conference: Heritage of Luria A.R. in contemporary scientific and cultural-historical context: To the 100 anniversary from birthday of Luria A.R. (pp. 70-92). Moscow: Faculty of psychology of Lomonosov Moscow State University.

LeDoux, J. E. (Ed.). (1996). The Emotional Brain. New York, NY: Simon \& Schuster.

Lenzenweger, M. F. (2010). Schizotypy and Schizophrenia: The View from Experimental Psychopathology. New York, NY: Guilford Press.

Luria, A. R. (1973a). Osnovy neiropsikhologii [Fundamentals of neuropsychology]. Moscow: Moscow University Press.

Luria, A. R. (1973b). Schema neiropsikhologicheskog oissledovania [Scheme of neuropsychological research]. Moscow: Moscow University Press.

Marceli, D. (1998). Depression de l'adolescent [Depression in adolescents]. Perspective Psy, $37(4), 241-248$.

Oleichik, I. V. (2011). Psikhopatologia, tipologia i nozologicheskaya otsenka yunosheskikh endogennykh depressiy (kliniko-katamnesticheskoe issledovanie) [Psychopathology, typology and nosological evaluation of adolescent endogenous depressions (clinic-catamnestic research). Zhurnal nevrologii i psikhiatrii imeni S.S. Korsakova [S.S. Korsakov Journal of Neurology and Psychiatry], 2, 10-18.

Raine, A., Lencz, T., \& Mednick, S. (Eds.). (1995). Schizotypal Personality. New York, NY: Cambridge University Press.

Ritsner, M. S. (Ed.). (2011). Handbook of Schizophrenia Spectrum Disorders (Vol. I). New York, NY: Springer.

Rohde, P., Lewinsohn, P. M., \& Seeley, J. R. (1994). Are adolescents changed by an episode of major depression? Journal of the American Academy of Child and Adolescent Psychiatry, 33(9), 1289-1298. doi: 10.1097/00004583-199411000-00010

Rohde, P., Lewinsohn, P. M., \& Seeley, J. R. (1991). Comorbidity of unipolar depression: II. Comorbidity with other mental disorders in adolescents and adults. Journal of Abnormal Psychology, 100(2), 214-222. doi: 10.1037/0021-843X.100.2.214

Ruocco, A. C. (2005). The neuropsychology of borderline personality disorder: a meta-analysis and review. Psychiatry Research, 137(3), 191-202. doi: 10.1016/j.psychres.2005.07.004

Sidorova, M. A., Kaleda, V. G., \& Barkhatova, A. N. (2004). Osobennosti neirokognitivnykh rasstroystv u bolnykh shizoaffektivnym psikhozom i pristupoobraznoys hizofreniey yunosheskogo vozrasta [Neurocognitive disorders characteristics in patients with schizoaffective psychosis and recurrent schizophrenia during adolescence]. Psikhiatriya [Psychiatry], 6(12), 15-21. 
Smulevich, A. B. (2009). Maloprogredientnaya shizofrenia i pogranichnye sostoyania [Continuous sluggisgschizophrenia and borderline states]. Moscow: MEDpress-Inform.

Smulevich, A. B. (2007). Rasstroystva lichnosti [Personality disorders]. Moscow: MEDpressInform.

Vladimirova, T. V. (1987). Yunosheskie depressii (diagnostika, tipologia i voprosy prognosa) [Adolescent depressions (diagnostics, typology and questions of prognosis]. Moscow.

Zvereva, N. V. (1998). Kompleksnoe izuchenie taktilnoii sfery zdorovykh i bolnykh s hizofreniey detei [Comprehensive study of tactile sphere in healthy people and patients with schizophrenia]. In T.V. Akhutina \& E.D. Homskaya (Eds.), First International A.R. Luria Memorial Conference [Collection of Selected Contributions] (pp. 358-365). Moscow: Russian Psychological Society.

Original manuscript received April 28, 2014 Revised manuscript accepted February 29, 2015

First published online June 30, 2015 